\title{
ECONOMIC EFFECT OF CLIMATE ALTERATION ON GRAIN PRODUCTION IN IRAN
}

\author{
SAEI, M. ${ }^{12^{*}}-$ MOHAMMADI, H. ${ }^{1}-$ ZIAEE, $S .{ }^{1}-$ BARKHORDARI, S. ${ }^{3}$ \\ ${ }^{I}$ Department of Agricultural Economics, Faculty of Agriculture, University of Zabol, Zabol, Iran \\ ${ }^{2}$ Economic, Social and Extension Research Department, Kerman Agricultural and Natural \\ Resources Research and Education Center, AREEO, Kerman, Iran
}

${ }^{3}$ Faculty of Economics, University of Tehran, Tehran, Iran

*Corresponding author

e-mail: mahdiyeh.saei@uoz.ac.ir

(Received $2^{\text {nd }}$ Jul 2018; accepted $13^{\text {th }}$ Sep 2018)

\begin{abstract}
The present study shows the economic effects of climate alteration on grain (maize, wheat, and rice) production in Iran using a Ricardian method. The model was estimated using the longitudinal data on grain yields and climate variables from 1983-2014. The marginal effects of climate changes on productivity of crops were estimated by applying Panel Corrected Standard Error (PCSE) models. Empirical results showed a considerable hill-shaped correlation between wheat yield and spring and fall rainfalls and temperatures. The joint effect of the spring and fall rainfall and temperature for wheat was significantly negative. For maize, the outcomes showed a considerable hill-shaped correlation between crop productivity and spring precipitation. Moreover, there was a meaningful interaction term between winter rainfall and temperature at $1 \%$. Our results for maize yield were not as robust as those for wheat. For rice, winter temperature had a considerable U-shaped relationship with rice yield, while summer precipitation and temperature had a considerable hill-shaped relationship with yield. The annual marginal impacts of rainfall and temperature for all the crops were positive. The outcomes showed that in Iran, the sensitivity of cereal production to enhance in precipitation levels would be less compared to the increase in temperature.
\end{abstract}

Keywords: climate change, grain yield, panel regression, ricardian method

\section{Introduction}

One of the global concern is climate change due to its impending threats to sustainable economic development. The effects of climate variations are more severe on agriculture compared to other economic activities (Stern, 2006; Mendelsohn et al., 2006; Rosenzweig and Iglesias, 1994; Adams et al., 1998; Cline, 2007; Nelson et al., 2009; Kurukulasuriya and Ajwad, 2007; De Salvo et al., 2013). The effects are probably too strong for developing nations, because of their strong dependency on agriculture and absence of economic resources for reducing and adapting to climate alteration (Mendelsohn et al., 2006; Stern, 2006; Nelson et al., 2009). Studies suggests that climate variation will considerably impact the agriculture sector of developing nations, leading to serious consequences in food safety and production. It would also have adverse effects on enormous population along with more effects on poor farmers with small farms.

\section{Review of literature}

Many researchers have measured the effects of climate variables on crop yield via simulation models for example CERES-rice, CERES-maize, and EPIC models (Phillips et al., 1996; Rosenzweig et al., 2002; Tan and Shibasaki, 2003) or regression models 
(Mendelsohn et al., 1994; Chang, 2002; Haim et al., 2008). Previous studies have generally employed two major approaches to assess the effect of climate on agriculture: the approach of production function (agronomic model or crop modeling) (Mearns et al., 1997), and the Ricardian approach (Mendelsohn et al., 1994). Employing controlled experiments, the first approach simulates data on crop yields and climate variables in a laboratory. With a precise control and randomized usage of environmental circumstances, this method can anticipate the climatic influences on agriculture yields. However, it does not consider farmers' attitudes towards climate change adaptation. This leads to overestimation of negative effects and underestimation of positive impacts (Adams et al., 1990, 1999; Haim et al., 2008; Mendelsohn et al., 1994). On the contrary, the Ricardian model estimates the association among values of land and agro-climatic variables through cross-sectional information (Kumar and Parikh, 1998; Mendelsohn et al., 1994). The major power of the Ricardian model is that it considers farmers' adaptations which influence land values as measured by farm earnings or net revenue. The model has been used in different countries, namely the USA (Mendelsohn and Dinar, 2003; Mendelsohn et al., 1994), England and Wales (Maddison, 2000); Kenya (Mariara and Karanja, 2007), Taiwan (Chang, 2002), South Africa (Gbetibouo and Hassan, 2005), Cameroon (Moula, 2009), China (Wang et al., 2009), and India and Brazil (Sanghi and Mendelsohn, 2008). Nevertheless, the approach, in its main form, may not be used for most developing countries since there are no influential land markets and reasonable land expenses in these countries.

Although the research about climate outcomes on Iranian agriculture is restricted, it is rising. In coming sections, we review the studies conducted on the influence of climate variation on agricultural crop productivity in developing nations generally, continued by reviewing of studies in Iran.

Liangzhi et al. (2005) studied climate effect on Chinese wheat yields using crop specific cross-section and time series data over 1979-2000 for main wheat generating provinces in China along with climate data like solar radiation, rainfall, and temperature during this period. They observed that $1 \%$ enhance in the heat in the germination season of wheat reduced wheat yields by almost $0.3 \%$. They also report that rising temperatures over the two decades prior to their research accounted for a $2.4 \%$ reduction in wheat productivities in China while a major growth in wheat yields (i.e., 75\%) is induced by increasing application of physical inputs.

Guiteras (2009) estimated the influence of climate variation on Indian agriculture with the feasible generalized least squares (FGLS) approximation method. His results offer that climate variation is probable to impose considerable costs on the Indian economy unless producers can quickly distinguish and adjust with temperature rises. The study also declared that such a quick adaptation might be fewer probable in a developing country, where availability of capital and information for adjustment is limited.

Ayinde et al. (2010) studied climate variation and agricultural crops in Nigeria using time series data. They used descriptive statistics and a Granger causality test analysis as analytical tools. According to their results, the temperature remains relatively constant and has no effect on agricultural output. However, using the Granger causality approach in their research revealed that alterations in precipitation positively affected agricultural crops in Nigeria.

Lee et al. (2012) evaluated the climate variation effects on agricultural crops in Asia over 1998-2007. They applied agricultural crop model and estimated a country-level 
constant impact panel model for agricultural crops by seasonal climate and other input variables. Their outcomes showed that greater temperatures and higher precipitation in summer increased agricultural crops while a decrease in temperatures was dangerous in South and Southeast of Asia. Moreover, they reported that a general enhance in annual temperature decreased agricultural crops in Asia. They stated that adapting to climate alteration through development new varieties with more tolerance to greater temperatures was essential. Moreover, they suggested increasing investments in agricultural productivity and expansion of appropriate adaptation programs or strategies.

Kumar and Sharma (2013) analyzed the climate alteration effects on agriculture sector productivity, the production value, and food safety in India according to secondary information over 1980-2009. They performed a regression analysis with the Cobb-Douglas production type model. They revealed that climate variations had harmful effects on lots of the food and non-food grain products in quantity and production value terms. The reported negative influences of climate alteration on the agricultural crops and food grains value shows food security risks to marginal farming households. Moreover, the research reported an econometric estimating of the statewise food security measure, revealing the harmful impacts of climatic variations on food safety.

Vaseghi and Esmaeili (2008a) studied the outcomes of climate alteration on agriculture in Iran, using chronological combined series of climate data over 1984-2004 and Ricardian model in 17 provinces and reported that climatic alterations had a considerable and nonlinear impact on net income per hectare of wheat. Moreover, they illustrated that the rise in temperature and fall in precipitation in the following 100 years would cause the decrease in yields per hectare by $41 \%$.

Elsewhere, Vaseghi and Esmaeili (2008b) applied the Ricardian scheme to measure the economic outcomes of climate alteration on maize production in 11 Iranian provinces for 1990 to 2004. They reported that climatic variables had considerable nonlinear effects on net income of maize. In addition, they demonstrated that the increase in temperature and fall in precipitation during the future 100 years would cause a $29 \%$ decrease in the maize yield (584 thousand Rials per hectare).

Sabzevary et al. (2012) examined the impacts of climatic variables on dry farming and irrigated wheat yields in selected stations of Hamadan Province, Iran. The investigation was performed by bivariate linear regression technique and the impact of all factors on wheat productivity was compared utilizing explanatory and correlative coefficients. Overall, the dry farming wheat yields index sensitivity to agroclimatic and atmospheric parameters was greater than irrigated wheat.

Pahrizkari et al. (2014) evaluated the climate alteration effect and consuming agricultural inputs (seeds, fertilizers, poisons, machinery) on the irrigated wheat yield over 2001-2013 in Shahrood watershed of Iran. The outcomes showed that increasing temperature over the generation season negatively affected the yield of wheat so that through enhancing the temperature, the yield of this crop has declined by $0.683 \%$. Also, they showed a considerable relation between the yield of wheat and inputs consumption.

Agriculture sector of Iran, despite its decreasing share in countrywide income, counts for almost $18 \%$ of national GDP, $85 \%$ of the food supply, above $20 \%$ of employment, $25 \%$ of non-oil products, and $90 \%$ of feedstock utilized in agro-industry (NCCOI, 2014). Therefore, incomes of a main group of people depend on agriculture that are in danger because of considerable negative influences of climate alteration on agriculture. 
The objective of this study is, thus, to assess the impacts of climate alteration on the yields of major grain crops (wheat, maize, and rice) of Iran using panel data. In this regard, a Richardian model is employed.

\section{Materials and methods}

Wheat growing regions in Iran are divided into four main climates in terms of weather conditions and cultivars: hot and humid, hot and arid, temperate, and cold climate. Irrespective of the growth habits of the cultivars (winter, spring, and intermediate), wheat in Iran is generally grown in autumn. In hot and humid climate, its sowing date is mid-November to mid-December and it is harvested in late-May. In hot and arid climate, it is sown in mid-December and harvested in mid-April. Temperate climate itself is sub-divided into northern and southern regions due to its stretch. In the northern regions, it is sown in late-October to late-November and in the southern regions, it is sown from November 6 until December 6. The harvest time is late-May to late-June. Wheat in cold climate is sown in late-December to mid-October and it is harvested in late-May to early-July.

Maize is a crop of tropics and subtropics and unlike other grains, it requires high temperatures and solar heat from sowing until harvest. In Iran, maize can be grown in most regions (hot, temperate, and cold). It may be sown in spring or summer depending on the regional climate and sowing type. Maize is mainly planted as a second crop after harvesting wheat. The sowing date of maize as the first crop varies from June 10 to June 20, and its sowing date as the second crop is July 11 in temperate regions. In hot regions, summer maize is sown from mid-July to early-August and spring maize is sown from late-February until mid-March. In cold regions, maize is planted in earlyMay. In all regions, maize is harvested about 4 months later.

Forty percent of total rice production in Iran is accounted for by Mazandaran province. The first crop starts in late-March in all provinces and it is finally harvested in late-July to mid-August. In recent years, farmers in some cities in the north of Iran prepare their farms for the second crop of rice immediately after harvesting the first crop. The second crop is harvested in October-November.

\section{The data}

Longitudinal data regarding three major grain yields and climate variables (i.e., rainfall and temperature) from chosen provinces in Iran were applied for estimating the model. The number of provinces selected for all crops was 5 for rice, 15 for wheat, and 9 for maize. The bases of including these provinces in the study have been the 'major grain-producing provinces' and accessibility of data for a minimum period of 30 years from 1983 to 2014 . Data on crop productivity measured in kilograms per hectare $(\mathrm{kg} / \mathrm{ha})$ were prepared from the Agricultural Jihad Ministry. Province-level climate information for monthly average temperature and monthly total precipitation were gathered from the Iran Meteorological Organization (IRIMO). Then, the monthly data were applied to group the climate factors into seasonal averages for rainfall and temperature for three crops. Crop productivities are usually reported for the production year, which is resembling to the financial year. So, the years were merged for the simplicity of analysis. Thus, for example, rice yield data in 1982-83 were considered as the yield for the year 1983. Accordingly, climate factors were in accordance with the yield data. Although yields depend on numerous factors, only climate variables (i.e., rain and 
temperature) were noticed in this research. Other factor inputs such as fertilizer, seed, and herbicides could have been involved but these were not existent on a crop-by-crop basis. Data related to the crop productivity and climate variables utilized in the present research are displayed in Table 1. According to the descriptive statistics of the model for a 30-year period, the average yield of wheat, maize and rice in Iran are 2920, 5175 and $3826 \mathrm{~kg} \mathrm{ha}^{-1}$. In wheat-producing provinces, mean temperature is 14, 27, 16 and $4{ }^{\circ} \mathrm{C}$ and mean precipitation is $118,7,60$ and $122 \mathrm{~mm}$ in spring, summer, autumn, and winter, respectively. In the case of maize producing provinces, the mean temperature in these seasons is $17,29,18$ and $6{ }^{\circ} \mathrm{C}$ and the mean precipitation is 100,2, 54 and $130 \mathrm{~mm}$, respectively. These are 18, 29, 20 and $9{ }^{\circ} \mathrm{C}$ and 121, 52, 230 and $235 \mathrm{~mm}$ for rice-producing provinces, respectively.

\section{Methodology}

The Ricardian log-linear model applied in current research is an empirical method proposed by Mendelsohn et al. (1994) for measuring the economic effect of climate variation on grain production in Iran. The technique was called after Ricardo due to his innovative results that the land value would reveal its net productivity at a situation under perfect competition. This method that predicts the impacts of climate and other factors on land values and farm incomes, has been generally utilized in various researches (Mendelsohn et al., 1994 and 1999; Sanghi and Mendelsohn, 1999; Gbetibouo and Hassan, 2005; Kurukulasuriya and Ajwad, 2007; Mendelsohn and Reinsborough, 2007).

The approximated variations in productivity resulted by alterations in ecological factors are accumulated with the total national effect (Olsen et al., 2000) or combined with an economic scheme for simulating the yield variations welfare effects under diverse climate variation scenarios (Kumar and Parikh, 1998; Chang, 2002). This model provides the probability of accounting the direct influence of climate alteration on crop productivities and the indirect replacement between diverse inputs contain introducing several activities, and other possible adaptations to climate alterations by direct measurement of farm costs or incomes (Deressa and Hassan, 2009). Applying Ricardian method, net incomes were regressed on climate parameters for identifying the effects of climate in explanation of net incomes.

The Ricardian method includes determining a net productivity function of the subsequent form (Eq. 1):

$$
\pi=\sum P_{i} Q_{i}(X, C, Z)-\sum P_{x} X
$$

where $\pi$ is the net income per hectare, $P_{i}$ is the price of crop i, $Q_{i}$ is output of crop i, X represents a purchased inputs vector (excluding land), $\mathrm{C}$ represents a climate factors vector, $\mathrm{Z}$ represents a vector for other control factors related with the farm including seeds and economic factors like market accessibility, and $P_{x}$ represents an input prices vector. The producer is expected to select $\mathrm{X}$ for maximizing net incomes considering the features of the farm and prices.

Resolving Equation 1 causes a decreased type model (Eq. 2$)$ in which net income is a function of all the exogenous factors $P_{i}, P_{x}, \mathrm{Z}$, and $\mathrm{C}$ : 


$$
\pi=R\left(P_{i}, P_{x}, C, Z\right)
$$

The empirical model applied in current research was a log-linear description of the Ricardian methodology (Eq. 3):

$$
\ln \pi=\beta_{0}+\beta_{1} T+\beta_{2} T^{2}+\beta_{3} P+\beta_{4} P^{2}+\beta_{5} T \times P+\varepsilon
$$

where $T$ and $P$ represent vectors for seasonal temperatures and rainfalls, and $\varepsilon$ represents an error expression. The square and interaction expressions related to climatic factors are showed in the model to see if there is any nonlinearity in the impacts of mentioned parameters on the crop yield. In the log-linear functional model, the linear coefficients offer approximations for the proportional alteration in $\pi$ for a change in the climate parameter and the quadratic terms related to rainfall and temperature reveals the nonlinear shape related to the response function between climate and net incomes (Eq.3). When the net income function has a $U$ shape, the quadratic term has a positive value, while in the case of having negative value for the quadratic term, the function has a hill shape. According to agronomic study and earlier cross-sectional analyses, a hill shape for correlation with temperature is expected for the farm value. Since there is a specific temperature at which a specific crop has its optimal growth over the seasons, products frequently show a hill-shaped relation with the yearly temperature. However, the correlation of seasonal climate factors is more complicated and may contain a mix of negative and positive coefficients over seasons. The predicted marginal effect of only one climate factor on net income of the farm assessed at the mean of factor is $(E q .4)$ :

$$
\left(\partial \pi / \partial C_{j}\right)=\left(\alpha_{1 j}+2 \beta_{2 j} \times \mathrm{C}\right) \times \pi
$$

The alteration in yearly welfare, $\Delta W$, causing by a climate variation from $C_{0}$ to $C_{1}$ can be calculated as following (Eq. 5):

$$
\Delta W=\pi\left(C_{1}\right)-\pi\left(C_{0}\right)
$$

where $\pi$ is the expected net income under the coming climate situation, $C_{1}$ represents the forecasted level for climate factors (rainfall or temperature), $C_{0}$ shows the normal mean temperature under the present climate situation, and $\Delta W$ represents the difference between the forecasted value of net income per hectare under the upcoming climate situation and the existing climate situation. Farm-level net-revenues, which reveal the modifications done by farmers for the normal climate conditions, can be employed to evaluate the climate response function. However, no such information is accessible for Iran. Hence, this study uses annual yield in the approximation of climate response function and other descriptive variables are taken in the similar ways. Similar to state level constant impact determined by Kumar (2009) while analyzing Indian agriculture and country-level fixed effects specified by Deschenes and Greenstone (2007) while analysing of US agriculture, we specified a district level constant-effect panel regression in the existing research. The Hausman specification test also confirms for the same. If there is AR cross-sectional dependence along with heteroscedasticity, FGLS with fixed effects was recognized to be an appropriate method of estimation. 
However, one of the disadvantages of FGLS estimation is that it generates excessively optimistic standard error estimates. Furthermore, the estimates are only feasible if $\mathrm{N}<\mathrm{T}$, suggesting that there are less number of observations comparing to the number of time period, which is not the case for the three crops. In this regard, Beck and Katz (1995) propose using Panel Corrected Standard Errors (PCSE) models with Monte Carlo analysis. These models work well and yield correct estimates of sampling variability even in the existence of complicated panel error structures. Following Beck and Katz (1995), this study employs the PCSE model for measuring the impacts of climate variation on the yield of major cereal crops in Iran.

Table 1. Summary statistics of yields and climate variables applied in the Ricardian model. (Source: Research findings)

\begin{tabular}{|c|c|c|c|c|c|c|c|}
\hline & Variables & Unit & $\mathbf{N}$ & Mean & Std. dev. & Min. & Max. \\
\hline \multirow{9}{*}{ Wheat } & Yield & $(\mathrm{Kg} / \mathrm{ha})$ & 480 & 2919.52 & 888.54 & 902.4 & 5732.81 \\
\hline & Spring temperature & $\left({ }^{\circ} \mathrm{C}\right)$ & 480 & 14.40 & 4.078 & 5.83 & 28.16 \\
\hline & Summer temperature & $\left({ }^{\circ} \mathrm{C}\right)$ & 480 & 27.02 & 3.74 & 20.5 & 38.6 \\
\hline & Fall temperature & $\left({ }^{\circ} \mathrm{C}\right)$ & 480 & 16.33 & 3.77 & 10.13 & 28.33 \\
\hline & Winter temperature & $\left({ }^{\circ} \mathrm{C}\right)$ & 480 & 3.59 & 4.18 & -6.1 & 15.63 \\
\hline & Spring precipitation & $(\mathrm{mm})$ & 480 & 117.62 & 63.70 & .3 & 315 \\
\hline & Summer precipitation & $(\mathrm{mm})$ & 480 & 6.98 & 11.64 & 0 & 65.4 \\
\hline & Fall precipitation & $(\mathrm{mm})$ & 480 & 60.18 & 53.96 & 0 & 395.5 \\
\hline & Winter precipitation & $(\mathrm{mm})$ & 480 & 122.51 & 70.38 & 4.7 & 556 \\
\hline \multirow{9}{*}{ Maize } & Yield & $(\mathrm{Kg} / \mathrm{ha})$ & 288 & 5175.57 & 2251.49 & 259.81 & 11250 \\
\hline & Spring temperature & $\left({ }^{\circ} \mathrm{C}\right)$ & 288 & 16.58 & 3.78 & 8.8 & 28.16 \\
\hline & Summer temperature & $\left({ }^{\circ} \mathrm{C}\right)$ & 288 & 29.05 & 3.21 & 22.93 & 38.6 \\
\hline & Fall temperature & $\left({ }^{\circ} \mathrm{C}\right)$ & 288 & 18.51 & 3.27 & 13.66 & 28.33 \\
\hline & Winter temperature & $\left({ }^{\circ} \mathrm{C}\right)$ & 288 & 6.54 & 3.45 & -3.63 & 15.63 \\
\hline & Spring precipitation & $(\mathrm{mm})$ & 288 & 100.26 & 73.75 & .3 & 315 \\
\hline & Summer precipitation & $(\mathrm{mm})$ & 288 & 2.23 & 4.37 & 0 & 26.5 \\
\hline & Fall precipitation & $(\mathrm{mm})$ & 288 & 53.84 & 61.83 & 0 & 395.5 \\
\hline & Winter precipitation & $(\mathrm{mm})$ & 288 & 130.13 & 83.15 & 4.1 & 556 \\
\hline \multirow{9}{*}{ Rice } & Yield & $(\mathrm{Kg} / \mathrm{ha})$ & 160 & 3826.19 & 763.81 & 2001.07 & 5699.97 \\
\hline & Spring temperature & $\left({ }^{\circ} \mathrm{C}\right)$ & 160 & 17.69 & 4.31 & 12.13 & 28.16 \\
\hline & Summer temperature & $\left({ }^{\circ} \mathrm{C}\right)$ & 160 & 28.97 & 4.56 & 22.93 & 38.6 \\
\hline & Fall temperature & $\left({ }^{\circ} \mathrm{C}\right)$ & 160 & 20.29 & 3.42 & 15.2 & 28.33 \\
\hline & Winter temperature & $\left({ }^{\circ} \mathrm{C}\right)$ & 160 & 9.02 & 2.59 & 4.67 & 15.63 \\
\hline & Spring precipitation & $(\mathrm{mm})$ & 160 & 121.40 & 82.61 & .3 & 427.8 \\
\hline & Summer precipitation & $(\mathrm{mm})$ & 160 & 51.89 & 76.68 & 0 & 320.4 \\
\hline & Fall precipitation & $(\mathrm{mm})$ & 160 & 229.62 & 239.82 & 0 & 996.4 \\
\hline & Winter precipitation & $(\mathrm{mm})$ & 160 & 235.36 & 133.90 & 26.3 & 598 \\
\hline
\end{tabular}

\section{Results}

The independent factors utilized in the scheme are linear, quadratic, and interaction terms between precipitation and temperature. Cross-sectional dependency is detected using Pesaran test. The Wooldridge autocorrelation test signs for the autocorrelation and Wald test signs for the heteroscedasticity. The panel unit root test presents that the 
factors we used are unit root free variables. To overcome the autocorrelation, crosssectional dependency, and heteroscedasticity problem, we estimated two econometric models: Feasible Generalized Least Squares (FGLS) and Prais-Winsten models with Panel Corrected Standard Errors (PCSE).

Tables 2, 3, and 4 present the outcomes of panel regression with district constant impacts for wheat, maize, and rice crop productivity, respectively. We compared the obtained PCSE and FGLS and, as expected, detected that the standard errors of FGLS are lower comparing to those of PCSE for nearly all estimates. This evidence, compatible with the findings of Beck and Katz (1995), shows that FGLS underestimates the standard errors. Therefore, we study only the PCSE estimates in discussing results and making inferences.

Table 2. Regression coefficients of climate factors for wheat crop

\begin{tabular}{|c|c|c|c|c|}
\hline \multirow[b]{2}{*}{ Variables } & \multicolumn{2}{|c|}{ FGLS } & \multicolumn{2}{|c|}{ PCSE } \\
\hline & Coefficients & Std. err. & Coefficients & Std. err. \\
\hline Constant & $7.575 * * *$ & 0.53 & $7.028 * * *$ & 0.905 \\
\hline Spring temp. & $0.0526 * * *$ & 0.020 & 0.0524 & 0.039 \\
\hline Spring temp. sq. & $-0.0022 * * *$ & 0.0006 & $-0.0019 *$ & 0.0011 \\
\hline Summer temp. & -0.085 & 0.047 & -0.037 & 0.080 \\
\hline Summer temp. sq. & $0.0017 * *$ & 0.00086 & 0.00080 & 0.0014 \\
\hline Fall temp. & $0.0938 * * *$ & 0.023 & $0.080 * *$ & 0.040 \\
\hline Fall temp. sq. & $-0.0024 * * *$ & 0.00066 & $-0.0020 *$ & 0.0011 \\
\hline Winter temp. & $0.0186^{* * *}$ & 0.0047 & $0.0256 * * *$ & 0.0091 \\
\hline Winter temp. sq. & -0.000052 & 0.00040 & -0.00037 & 0.00084 \\
\hline Spring prec. & $0.0027 * * *$ & 0.00054 & $0.0035^{* * *}$ & 0.00099 \\
\hline Spring prec. Sq. & $-3.96 \mathrm{e}-06^{* * *}$ & $9.42 \mathrm{e}-07$ & $-5.5 \mathrm{e}-06 * * *$ & $1.79 \mathrm{e}-06$ \\
\hline Summer prec. & -0.0079 & 0.0055 & -0.0054 & 0.0096 \\
\hline Summer prec. Sq. & $2.44 \mathrm{e}-06$ & 0.000026 & -0.0000109 & 0.000052 \\
\hline Fall prec. & $0.00083 * *$ & 0.00039 & 0.00073 & 0.00077 \\
\hline Fall prec. Sq. & $2.12 \mathrm{e}-06^{* *}$ & $8.69 \mathrm{e}-07$ & $2.88 \mathrm{e}-06$ & $1.95 \mathrm{e}-06$ \\
\hline Winter prec. & 0.00030 & 0.00020 & 0.000054 & 0.00040 \\
\hline Winter prec. Sq. & $-3.69 e-07$ & $4.88 \mathrm{e}-07$ & $-2.95 e-07$ & $8.15 \mathrm{e}-07$ \\
\hline Spring temp*prec & $-.0000925 * * *$ & .0000259 & $-.00011 * * *$ & .000045 \\
\hline Summer temp*prec & .0003358 & .0002009 & .00025 & .00032 \\
\hline Fall temp*prec & $-.0000715 * * *$ & .0000202 & $-.000074 *$ & .000038 \\
\hline Winter temp*prec & $1.71 \mathrm{e}-06$ & .0000182 & $7.45 \mathrm{e}-06$ & .000031 \\
\hline Wald chi2(20) & 183.54 & & 65.70 & \\
\hline Prob $>$ chi 2 & 0.0000 & & 0.0000 & \\
\hline$R^{2}$ & & & 0.89 & \\
\hline
\end{tabular}

Log of yield is the dependent variable

$* * *, * *$ and $*$ indicate significance at $1 \%, 5 \%$, and $10 \%$ levels, respectively 


\section{Impacts of climate factors on wheat yield}

Table 2 presents the panel regressions for wheat yield. We discuss the PCSE regression estimates for explaining the influence of climate factors on wheat yield. The $\mathrm{R}^{2}$ value is 0.89 , which demonstrates that the climate variables in the model explain more than two-thirds of alterations in the crop yield. The PCSE regression results specify that the variables of temperature and precipitation in spring, autumn, and winter influenced wheat yield positively, but only the variables of temperature in autumn and winter and precipitation in spring were statistically significant. Further, the variables of the squared temperature of spring and autumn and squared precipitation of spring were negative and statistically significant; this means that the increase in these variables is related to the increase in wheat yield up to a threshold beyond which crop yield is negatively influenced. According to Thapa-Parajuli and Devkota (2016), assuming that all other conditions are constant, the increase in temperature resulted in the increase in wheat yield up to a certain threshold in Nepal. Since wheat in Nepal is sown in cold season, the increase in temperature of this season enhances the yield. The same trend is observed for precipitation. This result is supported by Attri and Rathore's (2003) study in India. Also, interaction between fall and spring climate are usually negative and considerable whereas summer and winter climate interaction impacts are positive but insignificant. Accordingly, the joint effect related to temperature and precipitation for the fall and spring damages the wheat yield significantly. It can be clarified that increasing temperature and precipitation of both fall and spring would cause the significant negative joint climatic impact in wheat yield in Iran. Thus, it can be asserted that the climate variation although initially promotes producing wheat in Iran, this trend terminates following a determined threshold level.

\section{Impacts of climate factors on maize yield}

The PCSE outcomes indicate that the increase in temperature and precipitation in spring, summer, and autumn, which are the growing seasons of grain maize in Iran, affects the yield of this crop positively, but only the variables of temperature and precipitation of spring are statistically significant. Also, the yield of maize is negatively and significantly influenced by the squared precipitation of spring and is positively and significantly influenced by the squared precipitation of autumn. So, we can say that the precipitation of spring improves the yield of maize up to a specific threshold and then it affects its yield adversely. Further, the winter precipitation shows a considerable undesirable effect on maize yield. The decrease in crop productivity per hectare with increasing winter precipitation specifies that the available level of rainfall is enough for planting. The interaction term between winter rainfall and temperature is significant at $1 \%$, suggesting that the winter rainfall impact on yield is affected by the degree of temperature and vice versa. We found that our results related to maize yield are not as robust as the findings related to wheat (Table 3).

\section{Impacts of climate factors on rice yield}

The yield of rice was positively and significantly influenced by the temperature and precipitation of summer, whereas it was negatively and significantly affected by the squared temperature and precipitation of this season. So, it can be said that the increase in these variables entails the enhancement of the crop yield up to a specific threshold, beyond which it starts to be lost. Saravanakumar (2015) indicated that precipitation had 
an inverse U-shaped relationship with rice yield. This implies that more precipitation can improve its yield up to a certain threshold, but further precipitation would influence it negatively. This sort of the quadratic relationship between precipitation and yield has been reported by Chen and Chang (2005) in Taiwan and by Auffhammer et al. (2012) and Gupta et al. (2012) in India. Saravanakumar (2015) reported an inverse U-shaped relationship between temperature and rice yield, too. These findings are in agreement with studies on the effect of higher temperature on rice crop during its vegetative phase (Morita et al., 2004). It has been documented that the increase in temperature over a critical threshold can result in the loss of rice yield (Dash and Hunt, 2007; Geethalakshmi et al., 2011). The temperature of winter had, also, a significant U-shaped relationship with crop yield (Table 4).

Table 3. Regression coefficients of climate factors for maize crop

\begin{tabular}{|c|c|c|c|c|}
\hline \multirow[b]{2}{*}{ Variables } & \multicolumn{2}{|c|}{ FGLS } & \multicolumn{2}{|c|}{ PCSE } \\
\hline & Coefficients & Std. err. & Coefficients & Std. err. \\
\hline Constant & $5.92 * *$ & 2.50 & 2.78 & 3.81 \\
\hline Spring temp. & $0.188 * * *$ & 0.074 & $0.214^{*}$ & 0.113 \\
\hline Spring temp. sq. & $-0.0042 * *$ & 0.0020 & -0.0039 & 0.0031 \\
\hline Summer temp. & -0.131 & 0.197 & 0.022 & 0.29 \\
\hline Summer temp. sq. & 0.0032 & 0.0034 & 0.00059 & 0.0051 \\
\hline Fall temp. & $0.204 *$ & 0.117 & 0.237 & 0.180 \\
\hline Fall temp. sq. & $-0.0057 *$ & 0.0030 & -0.0062 & 0.0046 \\
\hline Winter temp. & $-0.033 * * *$ & 0.025 & -0.038 & 0.042 \\
\hline Winter temp. sq. & -0.00041 & 0.0017 & -0.0023 & 0.0027 \\
\hline Spring prec. & 0.0023 & 0.0024 & $0.0066^{*}$ & 0.0038 \\
\hline Spring prec. Sq. & $-5.54 \mathrm{e}-06$ & $3.42 \mathrm{e}-06$ & $-0.0000128 * *$ & $5.15 e-06$ \\
\hline Summer prec. & 0.085 & 0.067 & 0.142 & 0.104 \\
\hline Summer prec. Sq. & $-0.0012 * * *$ & 0.00041 & -0.00073 & 0.00060 \\
\hline Fall prec. & $0.0025 * *$ & 0.0016 & 0.0016 & 0.0026 \\
\hline Fall prec. Sq. & $5.21 \mathrm{e}-06^{* *}$ & $2.18 \mathrm{e}-06$ & $6.84 \mathrm{e}-06^{*}$ & $3.86 \mathrm{e}-06$ \\
\hline Winter prec. & -0.00090 & 0.00071 & $-0.0022 * *$ & 0.0011 \\
\hline Winter prec. Sq. & $1.24 \mathrm{e}-06$ & $1.32 \mathrm{e}-06$ & $1.27 \mathrm{e}-06$ & $1.87 \mathrm{e}-06$ \\
\hline Spring temp*prec & $4.20 \mathrm{e}-06$ & .00011 & -.00012 & .000017 \\
\hline Summer temp*prec & -.0024 & .0024 & -.0048 & .0037 \\
\hline Fall temp*prec & $-.00016 * *$ & .000073 & -.00014 & .000117 \\
\hline Winter temp*prec & $0.00011 *$ & .000060 & $0.00028 * * *$ & .00010 \\
\hline Wald chi2(20) & 96.84 & & 65.70 & 59.97 \\
\hline Prob $>$ chi 2 & 0.0000 & & 0.0000 & 0.0000 \\
\hline$R^{2}$ & & & 0.54 & \\
\hline
\end{tabular}

Log of yield is the dependent variable

$* * *, * *$ and $*$ indicate significance at $1 \%, 5 \%$, and $10 \%$ levels, respectively 
Table 4. Regression coefficients of climate factors for rice crop

\begin{tabular}{|c|c|c|c|c|}
\hline \multirow[b]{2}{*}{ Variables } & \multicolumn{2}{|c|}{ FGLS } & \multicolumn{2}{|c|}{ PCSE } \\
\hline & Coefficients & Std. err. & Coefficients & Std. err. \\
\hline Constant & $4.56^{* * *}$ & 1.52 & $4.57 * * *$ & 1.83 \\
\hline Spring temp. & -0.073 & 0.063 & -0.055 & 0.077 \\
\hline Spring temp. sq. & 0.00099 & 0.00177 & 0.000086 & 0.0021 \\
\hline Summer temp. & $0.253 * *$ & 0.112 & $0.23 * *$ & 0.14 \\
\hline Summer temp. sq. & $-0.0040 * *$ & 0.0019 & $-0.0035 * *$ & 0.0025 \\
\hline Fall temp. & 0.121 & 0.107 & 0.153 & 0.127 \\
\hline Fall temp. sq. & -0.0023 & 0.0026 & -0.0032 & 0.0032 \\
\hline Winter temp. & $-0.122 * * *$ & 0.045 & $-0.166^{* * *}$ & 0.053 \\
\hline Winter temp. sq. & $0.0050 * *$ & 0.0022 & $0.0085^{* *}$ & 0.0027 \\
\hline Spring prec. & -0.0011 & 0.0012 & -0.0017 & 0.0015 \\
\hline Spring prec. Sq. & $2.41 \mathrm{e}-06^{* *}$ & $1.07 \mathrm{e}-06$ & $2.84 \mathrm{e}-06^{* *}$ & $1.32 \mathrm{e}-06$ \\
\hline Summer prec. & $0.0063^{*}$ & 0.0036 & $0.0055^{*}$ & 0.0042 \\
\hline Summer prec. Sq. & $-7.06 \mathrm{e}-06 * * *$ & $1.72 \mathrm{e}-06$ & $-8.01 \mathrm{e}-06 * * *$ & $1.99 \mathrm{e}-06$ \\
\hline Fall prec. & -0.0010 & 0.00076 & -0.0011 & 0.00090 \\
\hline Fall prec. Sq. & $2.23 e-07$ & $2.21 \mathrm{e}-07$ & $3.65 \mathrm{e}-07$ & $2.64 \mathrm{e}-07$ \\
\hline Winter prec. & -0.0010 & 0.00062 & -0.0010 & 0.00079 \\
\hline Winter prec. Sq. & $4.51 \mathrm{e}-08$ & $5.11 \mathrm{e}-07$ & $2.47 \mathrm{e}-07$ & $6.52 \mathrm{e}-07$ \\
\hline Spring temp*prec & $7.42 \mathrm{e}-06$ & .000066 & .000036 & .000082 \\
\hline Summer temp*prec & -.00017 & .00013 & -.00012 & .00016 \\
\hline Fall temp*prec & $.000056^{*}$ & .000034 & $.000052 *$ & .000041 \\
\hline Winter temp*prec & $0.000099 * *$ & .000050 & $0.000091 * *$ & .000065 \\
\hline Wald chi2(20) & 98.21 & & 65.70 & 75.79 \\
\hline Prob $>$ chi2 & 0.0000 & & 0.0000 & 0.0000 \\
\hline$R^{2}$ & & & 0.91 & \\
\hline
\end{tabular}

Log of yield is the dependent variable

$* * *, * *$ and $*$ indicate significance at $1 \%, 5 \%$, and $10 \%$ levels, respectively

To prevent the complicated analysis and explanation of climate factors because of quadratic and interaction terms, the computed marginal effects and elasticities of climate factors are shown in Tables 5 and 6 , respectively.

\section{Marginal effect analysis}

Table 5 presents the marginal effects of seasonal climate factors on cereal grain yields, which were assessed at the average. The magnitudes of the marginal effects show that at current levels of rainfall, enhancing temperature over the summer, fall, and winter seasons boost wheat yield. The marginal increase in spring temperature, however, reduce wheat yield. In addition, a rise in rainfall over the spring, summer, and 
winter seasons causes a positive marginal effect while a rise in rainfall during fall season causes a negative marginal impact on the wheat yield. Also, outcomes indicate that at present levels of rainfall, a rise in summer and spring temperatures would increase maize yield, while the same increase in fall and winter seasons would decrease the yield. Moreover, analyzing season precipitations for maize shows that spring rainfall causes a positive marginal effect but that of other seasons have a negative marginal effect.

Finally, marginal impacts for rice show that rising temperature in spring season has a significantly harmful effect on rice productivity. However, increasing temperatures of summer, fall, and winter has beneficial effects on rice yield. Also, increasing summer and fall precipitation increases rice yield. The annual marginal impacts of temperature and rainfall for each crop are positive.

Table 5. Marginal effects of climate factors on grain yield

\begin{tabular}{c|c|c|c}
\hline \multirow{3}{*}{ Crop } & \multirow{2}{*}{ Period } & \multicolumn{2}{|c}{ Climate variable } \\
\cline { 2 - 4 } & Spring & Temperature & Rainfall \\
\hline \multirow{4}{*}{ Wheat } & Summer & -0.018 & $0.00063^{* *}$ \\
& Fall & 0.0082 & 0.0013 \\
& Winter & 0.010 & -0.00013 \\
& Annual & 0.024 & $9.14 \mathrm{e}-06$ \\
& Spring & $0.072^{* * *}$ & 0.0018 \\
\hline \multirow{4}{*}{ Maize } & Summer & 0.046 & $0.0020^{* * *}$ \\
& Fall & -0.0021 & -0.00011 \\
& Winter & -0.032 & -0.00036 \\
& Annual & 0.083 & -0.000059 \\
& Spring & $-0.047^{* * *}$ & 0.0014 \\
\hline \multirow{4}{*}{ Rice } & Summer & 0.019 & -0.00039 \\
& Fall & $0.035^{* *}$ & 0.00098 \\
& Winter & 0.0096 & 0.000063 \\
& Annual & 0.017 & -0.00012 \\
& & & 0.00053 \\
\hline
\end{tabular}

$* * *, * *$ and $*$ indicate significance at $1 \%, 5 \%$, and $10 \%$ levels, respectively

Table 6 represents the elasticities of climate factors in the model. The regression coefficients and average values of climate factors were applied for computing elasticities of seasonal temperature and precipitation. The outcomes demonstrate that a $1 \%$ rise in temperature over the summer, fall, and winter will enhance yield by 0.027 , 0.021 , and $0.01 \%$, respectively, while the rise in temperature by $1 \%$ during the spring reduces yield by $0.033 \%$. Also, when the spring, summer, and winter precipitations are increased by $1 \%$, wheat yield increases by $0.00063,0.0013$, and $0.000009 \%$, respectively. However, rising rainfall over the fall season decreases yield by $0.00013 \%$. Elasticities of annual climate factors offer that higher temperature and more precipitation increase wheat yield by $0.024 \%$ and $0.0018 \%$, respectively.

In the case of maize, the results are different but the impacts of annual climate factors are similar. A $1 \%$ rise in temperature over the spring and summer increases yield by 0.139 and $0.157 \%$ but the same increase in fall and winter temperatures decrease 
yield by 0.0046 and $0.024 \%$, respectively. Besides, a $1 \%$ increase in rainfall during the spring increases yield by $0.0023 \%$. However, rainfall increase over the summer, fall, and winter reduces the maize yield.

Finally, the magnitudes of the elasticities show that a $1 \%$ rise in temperature over the summer, fall, and winter seasons would enhance rice productivity by $0.068,0.087$, and $0.01 \%$, respectively. However, the rise in temperature by a $1 \%$ during the spring would reduce yield by $0.1 \%$. The sum of elasticities is 0.065 showing that warming up of weather is beneficial for the rice yield. If annual average temperature rises by a $1 \%$, rice yield enhances by $0.065 \%$. Also, outcomes indicate that a $1 \%$ rise in rainfall over summer and fall seasons would increase rice yield by 0.0061 and $0.0017 \%$, while the same increase in spring and winter seasons would decrease rice yield by 0.0057 and $0.0035 \%$, respectively. The aggregate effect, i.e., the sum of all seasons, was found to decline the yield by $0.0013 \%$.

As observed, the rainfall impact on product yield is unimportant comparing to the temperature effect. This difference could be because of the application of irrigation to cultivate the crops.

Table 6. Elasticities of climate factors on the grain yield

\begin{tabular}{c|c|c|c}
\hline \multirow{3}{*}{ Crop } & \multirow{2}{*}{ Period } & \multicolumn{2}{|c}{ Climate variable } \\
\cline { 2 - 4 } & Spring & Temperature & Rainfall \\
\hline \multirow{4}{*}{ Wheat } & Summer & -0.033 & $0.0093^{* *}$ \\
& Fall & 0.027 & 0.0011 \\
& Winter & 0.021 & -0.00099 \\
& Annual & $0.01 * *$ & 0.00014 \\
& Spring & 0.093 & 0.094 \\
\hline \multirow{3}{*}{ Maize } & Summer & $0.139 * * *$ & $0.0023 * * *$ \\
& Fall & -0.0046 & -0.000029 \\
& Winter & -0.024 & -0.0022 \\
& Annual & 0.267 & -0.0009 \\
& Spring & $-0.1 * * *$ & 0.02 \\
\hline \multirow{3}{*}{ Rice } & Summer & 0.068 & -0.0057 \\
& Fall & $0.087 * *$ & 0.0061 \\
& Winter & 0.01 & 0.0017 \\
& Annual & 0.065 & -0.0035 \\
\hline
\end{tabular}

$* * *, * *$ and $*$ indicate significance at $1 \%, 5 \%$, and $10 \%$ levels, respectively

\section{Discussion}

The present research was conducted based on the Ricardian method to investigate the climate alteration impact on cereal production in Iran with emphasizing on wheat, maize, and rice crops. The outcomes based upon Prais-Winsten models with panels corrected standard errors (PCSEs) estimation offer that climatic change influences cereal production significantly; however, the impact varies across the crops. The marginal effect analysis revealed that a marginal temperature rise over the summer, winter, and fall seasons boost wheat yield, while a marginal temperature rise over the 
spring declines yield level. Also, a rise in rain throughout the spring, winter, and summer seasons have a positive impact while its rise throughout the fall shows a negative marginal influence on the wheat yield. The outcomes are somewhat different for maize from the wheat results. Outcomes demonstrated that at available levels of rainfall, a temperature rise throughout summer and spring seasons would increase maize yield, while the same increase in winter and fall seasons would decrease the yield. Besides, analyzing season precipitations for maize showed that spring rain has a positive marginal effect while that of other seasons show a negative marginal effect. Marginal impacts of rice indicated that rising temperature in spring season has a significantly harmful effect on rice productivity. However, the increase in summer, winter and fall temperatures affect beneficially on rice yield. Also, increasing summer and fall precipitation increases rice yield. The annual marginal effects relating to rainfall and temperature for all the crops are positive.

Furthermore, the outcomes ascertained that the cereal production in Iran are less sensitive to rising precipitation levels than rising temperature levels. This difference could be because of application of irrigation to cultivate the crops. Therefore, the impact of rainfall changes on these products is not fully clear. This result has considerable effects for appropriate adaptation processes and strategies. For instance, these outcomes offer that research on breeding for drought tolerance rather than heat tolerance should shape future agricultural research in the country.

The key outcome of the present analysis is that climate variation is beneficial for main cereal crops in Iran. Considering the results of current study, the crops yields will enhance based on the estimation model. Though the current study demonstrates that climate variation does not threaten the agriculture economy of Iran, this event can be hazardous if unsuitable adaptation policies are implemented. Thus, the agricultural strategies must be taking into account for encouraging farmers to use suitable practices and techniques against climate variation. These strategies should help farmers for developing irrigation approaches, select suitable crops, and face with water shortage. Adaptation can be carried out through different methods. First and main one is the extreme challenge, i.e., teaching farmers about the events of climate variation and its effects. Hence, more effective extension programs are required to promote farmers' awareness of climate variation. Certainly, inhibition of damages can occur through more effective farm planning. Crop insurance, different economic bases of areas dependent on agriculture and developed monitoring/predictions of climate will also enhance adaption of crops cope to future variations. These strategies, however, must considered the large seasonal changeability on the response of crops.

\section{Conclusion}

The current paper attempts to estimate the impact of climate alteration on cereal production in Iran. Our results suggests that warmer summers are beneficial to all crops studied in the current work. The effect of warmer springs is harmful to wheat and rice but beneficial to maize. Warmer falls are beneficial for wheat and rice but harmful to maize. Wetter spring have a tendency to enhance yields for wheat and maize and wetter summers increase yields for wheat and rice. The key outcome of the present analysis is that climate variation is beneficial for main cereal crops in Iran. Moreover, the research shows that there are limited data on the economic influence of climate variation on agriculture in Iran and further studies and deeper analyses are needed in this field. 
Acknowledgements. This research was supported by the research fund of University of Zabol Grant code: UOZ-GR-9517-4, whom the authors sincerely thank.

\section{REFERENCES}

[1] Adams, R. M., Rosenzweig, C., Pearl, R. M., Ritchie, J. T., McCarl, B. A., Glyer, J. D., Curry, R. B., Jones, J. W., Boote, K. J., Allen, L. H. (1990): Global climate change and U.S. agriculture. - Nature 345: 219-224.

[2] Adams, R. M., Hurd, B. H., Lenhart, S., Leary, N. (1998): Effects of global climate change on agriculture: An interpretative review. - Climate Research 11(1): 19-30.

[3] Adams, R. M., McCarl, B. A., Segerson, K., Rosenzweig, C., Bryant, K. J., Dixon, B. L., Connor, R., Evenson, R. B., Ojima, D. (1999): Economic Effects of Climate Change on U.S. Agriculture. - In: Mendelsohn, R., Neumann, J. E. (eds.) The Impact of Climate Change on the United States Economy. Cambridge University Press, Cambridge, UK, pp. 18-54.

[4] Attri, S. D., Rathore, L. S. (2003): Simulation of impact of projected climate change on wheat in India. - International Journal of Climatology 23: 693-705.

[5] Auffhammer, M., Ramanathan, V., Vincent, J. R. (2012): Climate change, the monsoon, and rice yield in India. - Climatic Change 111(2): 411-424.

[6] Ayinde, O. E., Adewumi, M. O., Ojehomon, V. E. T. (2010): Determinants of technical efficiency and varietal-gap of rice production in Nigeria: A meta-frontier model approach. - A paper prepared for presentation at the International Association of Agricultural Economists Conference, Beijing, China, August 16-22, 2009, pp. 1-21.

[7] Beck, N., Katz, J. N. (1995): What to do (and not to do) with time-series cross-section data. - The American Political Science Review 89(3): 634-647.

[8] Chang, C. C. (2002): The potential impact of climate change on Taiwan's agriculture. Agriculture Economics 27: 51-64.

[9] Chen, C. C.; Chang, C. C. (2005): The impact of weather on crop yield distribution in Taiwan: Some new evidence from panel data models and implications for crop insurance. - Agricultural Economics 33(3): 503-511.

[10] Cline, W. (2007): Global warming and agriculture: Impact estimates by country. Journal of Economic Literature 46(2): 448-450.

[11] Deressa, T. T., Hassan, R. M. (2009): Economic impact of climate change on crop production in Ethiopia: Evidence from cross-section measures. - Journal of African Economics 18(4): 529-554.

[12] De Salvo, M., Raffael, R., Moser, R. (2013): The impact of climate change on permanent crops in an Alpine region: a Ricardian analysis. - Agricultural Systems 118: 23-32.

[13] Deschenes, O., Greenstone, M. (2007): The economic impacts of climate change: Evidence from agricultural output and random fluctuations in weather. - The American Economic Review 97(1): 354-385.

[14] Dash, S. K., Hunt, J. C. R. (2007): Variability of climate change in India. - Current Science 93(6): 782-788.

[15] Gbetibouo, G. A., Hassan, R. M. (2005): Measuring the economic impact of climate change on major South African field crops: a Ricardian approach. - Global and Planetary Change 47(2): 143-152.

[16] Geethalakshmi, V., Lakshmanan, A., Rajalakshmi, D., Jagannathan, R., Sridhar, G., Ramaraj, A. P., Bhuvaneswari, K., Gurusamy, L. and Anbhazhagan, R. (2011): Climate change impact assessment and adaptation strategies to sustain rice production in Cauvery basin of Tamil Nadu. - Current Science 101(3): 342-347.

[17] Guiteras, R. (2009): The Impact of Climate Change on Indian Agriculture. - University of Maryland, College Park. 
[18] Gupta, SH., Sen, P., Srinivasan, S. (2012): Impact of climate change on the Indian economy: Evidence from food grain yields. - Working Paper No. 218, Centre for Development Economics, Department of Economics, Delhi School of Economics, New Delhi.

[19] Haim, D., Shechter, M., Berliner, P. (2008): Assessing the impact of climate change on representative field crops in Israel agriculture: A case study of wheat and cotton. Climate Change 86(3): 425-440.

[20] Kumar, K. (2009): Climate Sensitivity of Indian Agriculture: Do Spatial Effects Matter? - SANDEE Working Papers, 45-09. SANDEE, Kathmandu.

[21] Kumar, K., Parikh, S. (1998): Climate Change Impacts on Indian Agriculture: The Ricardian Approach. - In: Dinar, A., Mendelsohn, R., Evenson, R., Parokh, J., Sanghi, A., Kumar, K., McKinsey, J., Lonergan, S. (eds.) Measuring the Impact of Climate Change on Indian Agriculture. World Bank Technical Report No. 409, World Bank, Washington, DC.

[22] Kumar, A., Sharma, P. (2013): Impact of Climate Variation on Agricultural Productivity and Food Security in Rural India. - Economics Discussion Papers, No 2013-43, Kiel Institute for the World Economy, Kiel, Germany.

[23] Kurukulasuriya, P., Ajwad, M. I. (2007): Application of the Ricardian technique to estimate the impact of climate change on smallholder farming in Sri Lanka. - Climate Change 81: 39-59.

[24] Lee, J., Nadolnyak, D., Hartarska, V. (2012): Impact of climate change on agricultural production in Asian countries: Evidence from panel study. - Paper prepared for presentation at the Southern Agricultural Economics Association Annual Meeting, Birmingham.

[25] Liangzhi, Y., Rosegrant, M. W., Fang, CH., Wood. S. (2005): Impact of Global Warming on Chinese Wheat Productivity. - EPT Discussion Paper 143, International Food Policy Research Institute, Washington, DC.

[26] Maddison, D. (2000): A hedonic analysis of agricultural land prices in England and Wales. - European Review of Agricultural Economics 27(4): 519-532.

[27] Mariara, J. K., Karanja, F. K. (2007): The economic impact of climate change on Kenyan crop agriculture: a Ricardian approach. - Global and Planetary Change 57: 319-330.

[28] Mearns, L. O., Rosenzweig, C., Goldberg, R. (1997): Mean and variance change in climate scenarios: Methods, agricultural applications, and measures of uncertainty. Climate Change 35(4): 367-396.

[29] Mendelsohn, R., Dinar, A. (2003): Climate, water and agriculture. - Land Economics 79(3): 329-341.

[30] Mendelsohn, R., Reinsborough, M. (2007): A Ricardian analysis of US and Canadian farmland. - Climatic Change 81: 9-17.

[31] Mendelsohn, R., Nordhaus, W. D., Shaw, D. (1994): The impact of global warming on agriculture: a Ricardian analysis. - The American Economic Review 84(4): 753-771.

[32] Mendelsohn, R., Nordhaus, W. D., Shaw, D. (1999): The Impact of Climate Variation on US Agriculture. - In: Mendelsohn, R., Neumann, J. (eds.) The Impact of Climate Change on the United States Economy. Cambridge University Press, Cambridge, UK.

[33] Mendelsohn, R., Dinar, A., Williams, L. (2006): The distributional impact of climate change on rich and poor countries. - Environment and Development Economics 11(2): 159-178.

[34] Morita, S., Shiratsuchi, H., Takahashi, J., Fujita, K. (2004): Effect of high temperature on ripening in rice plant: analysis of the effect of high night and high day temperature applied to the panicle in other parts of the plant. - Japanese Journal of rice Science 73(1): 77-83.

[35] Moula, E. L. (2009): An empirical assessment of the impact of climate change on smallholder agriculture in Cameroon. - Global Planet Change 67(3): 205-208. 
[36] National Climate Change Office of Iran (NCCOI) (2014): Third National Communication to United Nations Framework Convention on Climate Change (UNFCCC). - Department of Environment. Available via: http://climate-change.ir.

[37] Nelson, G. C., Rosegrant, M. W., Koo, J., Robertson, R., Sulser, T., Zhu, T., Ringler, C., Msangi, S., Palazzo, A., Batka, M., Magalhaes, M., Valmonte-Santos, R., Ewing, M., Lee, D. (2009): Climate Change: Impact on Agriculture and Costs of Adaptation. - Food Policy Report, International Food Policy Research Institute, Washington, DC.

[38] Olsen, J. E., Bocher, P. K., Jensen, T. (2000): Comparison of scales of climate and soil data for aggregating simulated yields of winter wheat in Denmark. - Agriculture, Ecosystems and Environment 82(3): 213-28.

[39] Pahizikari, A., Mozaffari, M. M., Hosseini Khodadadi, M. (2014): Economic analysis of climate change on yield of irrigated wheat in Shahrood watershed. - Agricultural and Natural Resources Journal 18(4): 88-100.

[40] Phillips, D. L., Jeffrey, J. L., Rusty, F. D. (1996): Sensitivity of the US corn belt to climate change and elevated $\mathrm{CO}_{2}$ : I. Corn and soybean yields. - Agricultural Systems 52: 481-502.

[41] Rosenzweig, C., Iglesias, A. (eds.) (1994): Implications of Climate Change for International Agriculture: Crop Modelling Study. - US Environmental Protection Agency, Washington.

[42] Rosenzweig, C., Tubiello, F. N., Goldberg, R., Mills, E., Bloomfield, J. (2002): Increased crop damage in the U.S. from excess precipitation under climate change. - Global Environment Change 12: 197-202.

[43] Sabzevary, A., Torkaman, M., Meryanji, Z. (2012): Survey the effect of parameters and meteorological variables in optimal performance of wheat (A case study: Hamedan province). - Journal of Soil Water and Agriculture Science Technology 26(6): 15541567.

[44] Sanghi, A., Mendelsohn, R. (1999): The Impact of Global Warming on Brazilian and Indian Agriculture. - Yale School of Forestry and Environmental Sciences, New Haven, CT, USA.

[45] Sanghi, A., Mendelsohn, R. (2008): The impact of global warming on farmers in Brazil and India. - Global Environment Change 18(4): 655-665.

[46] Saravanakumar, V. (2015): Impact of Climate Change on Yield of Major Food Crops in Tamil Nadu, India. - SANDEE Working Papers, WP 91-15. SANDEE, Kathmandu.

[47] Stern, N. (2006): The Economics of Climate Change: The Stern Review. H. M. Treasury, London, TAC (Technical Advisory Committee of the CGIAR) (1992): A Review of CGIAR Priorities and Strategies Draft. - TAC Secretariat, FAO, Rome.

[48] Tan, G., Shibasaki, R. (2003): Global estimation of crop productivity and the impacts of global warming by GIS and EPIC integration. - Ecological Modeling 168(3): 357-370.

[49] Thapa-Parajuli, R. B., Devkota, N. (2016): Impact of climate change on wheat production in Nepal. - Asian Journal of Agricultural Extension, Economics and Sociology 9(2): 114.

[50] Vaseghi, E., Esmaeili, A. A. K. (2008a): Investigation of the economic impacts of climate change on Iran agriculture: a Ricardian approach (Case study: wheat). - Journal of Science and Technology of Agriculture and Natural Resources 12(45): 685-696.

[51] Vaseghi, E., Esmaeili, A. A. K. (2008b): Impacts of climate change on land rent: Case study of maize. - Economics and Agriculture Journal 2(3): 47-67.

[52] Wang, J., Mendelsohn, R. O., Dinar, A., Huang, J., Rozelle, S., Zhang, L. (2009): The impact of climate change on China's agriculture. - Agricultural Economics 40: 323-337.

[53] Wooldridge, J. (2002): Econometric Analysis of Cross Section and Panel Data. - MIT Press, Cambridge. 